The University of Southern Mississippi

The Aquila Digital Community

Faculty Publications

$9-1-2000$

\title{
Dynamical Balance in the Indonesian Seas Circulation
}

\author{
William H. Burnett \\ Stennis Space Center \\ Vladimir M. Kamenkovich \\ University of Southern Mississippi, vladimir.kamenkovich@usm.edu \\ David A. Jaffe \\ University of California \\ Arnold L. Gordon \\ Lamont-Doherty Earth Observatory of Columbia University \\ George L. Mellor \\ Princeton University
}

Follow this and additional works at: https://aquila.usm.edu/fac_pubs

Part of the Psychology Commons

\section{Recommended Citation}

Burnett, W. H., Kamenkovich, V. M., Jaffe, D. A., Gordon, A. L., Mellor, G. L. (2000). Dynamical Balance in the Indonesian Seas Circulation. Geophysical Research Letters, 27(17), 2705-2708.

Available at: https://aquila.usm.edu/fac_pubs/4104

This Article is brought to you for free and open access by The Aquila Digital Community. It has been accepted for inclusion in Faculty Publications by an authorized administrator of The Aquila Digital Community. For more information, please contact Joshua.Cromwell@usm.edu. 


\title{
Dynamical balance in the Indonesian Seas circulation
}

\author{
William H. Burnett \\ Naval Meteorology and Oceanography Command, Stennis Space Center, MS \\ Vladimir M. Kamenkovich \\ Department of Marine Science, The University of Southern Mississippi, Stennis Space Center, MS
}

David A. Jaffe

University of California, Irvine, CA

Arnold L. Gordon

Lamont-Doherty Earth Observatory of Columbia University, Palisades, NY

George L. Mellor

Program in Atmospheric and Oceanic Sciences, Princeton University, Princeton, NJ

\begin{abstract}
A high resolution, four-open port, non-linear, barotropic ocean model (2D POM) is used to analyze the Indonesian Seas circulation. Both local and overall momentum balances are studied. It is shown that geostrophy holds over most of the area and that the Pacific-Indian Ocean pressure difference is essentially balanced by the resultant of pressure forces acting on the bottom.
\end{abstract}

Burnett et al. [2000] described the initial results from the operation of a high-resolution, three-open port, non-linear, barotropic version of the Princeton Ocean Model [Blumberg and Mellor 1987] over the Indonesian Seas area. Results showed that the pressure difference between the $\mathrm{Pa}$ cific and Indian Ocean did not significantly influence the total transport of the Indonesian throughflow. It appeared that this pressure head was essentially balanced by the resultant of pressure forces acting on the bottom (the bottom form stress). The purpose of this note is to report the results from the addition of a fourth port modeling the New Guinea Coastal Current inflow, and to provide a quantitative analysis of the momentum balance in the model domain.

We incorporate four open ports to simulate the Mindanao Current (MC) inflow, the North Equatorial Countercurrent (NECC) outflow, the New Guinea Coastal Current (NGCC) inflow and the Indian Ocean (IO) outflow, see Fig. 1. To set up a coordinate system we will direct the $x$ - and $y$-axes along the southern and western boundaries of the domain, respectively. Table 1 provides information on the prescribed transports through the ports in the model domain covered by $250 \times 250$ grid cells at approximately $10 \mathrm{~km}$ resolution. In these simulations we do not consider the direct action of the wind stress.

Model specifics are provided in Burnett et al. [2000]. We perform two types of experiments. In the Type 1

Copyright 2000 by the American Geophysical Union.

Paper number 2000GL011494.

0094-8276/00/2000GL011494\$05.00 experiment, the normal and tangential velocities at the ports are prescribed. For this study, we select transports from a boreal winter throughflow of $5 \mathrm{~Sv}$, based on the results by Gordon and McClean [1999]. Miyama et al. [1995] and Fieux et al. [1996] provide historical and model observations of total transports of the Mindanao Current and Indian Ocean outflow respectively. Murray et al. [1995] provide observations of the New Guinea Coastal Current transport through the Vitiaz Strait, which are used in specifying the NGCC inflow. The North Equatorial Countercurrent balances the total inflow and outflow to ensure volume conservation within the model domain. The Type 1 experiment was run for a year, which is sufficient to reach a steady state. This experiment's steady state sea-surface elevations and velocities are used as boundary and initial-value conditions for the Type 2 experiment, where sea surface elevations and tangential velocities are specified at the open ports.

Figure 2 compares the Type 1 experiment's Coriolis acceleration to the pressure gradient across the MC port to demonstrate the applicability of the geostrophic approximation (the results for other ports are similar). This comparison substantiates the argument that changing the sea surface elevation across the ports by a constant value should not modify the total transport through the ports.

To locate ageostrophic conditions in the Indonesian Seas area, we calculate the relative error in the fulfillment of the geostrophic relations at each grid point over the entire domain. The relative error for $f U=-g \partial \eta / \partial y$ is given by:

$$
\text { Error }=\frac{\left[(f U+g \partial \eta / \partial y)^{2}\right]^{1 / 2}}{(0.5)^{1 / 2}\left[(f U)^{2}+(g \partial \eta / \partial y)^{2}\right]^{1 / 2}}
$$

where $f$ is the Coriolis parameter, $U$ is the $\mathbf{x}$-component of the velocity vector, and $\eta$ is the sea-surface elevation. Figure 1 shows the locations where the relative error (1) is greater than 0.1 indicating ageostrophic conditions. Ageostrophic conditions exist along the equator (where the Coriolis acceleration is absent) and along narrow straits (predominantly the Makassar Strait). Still, geostrophic conditions exist basically throughout the model domain. Similar 


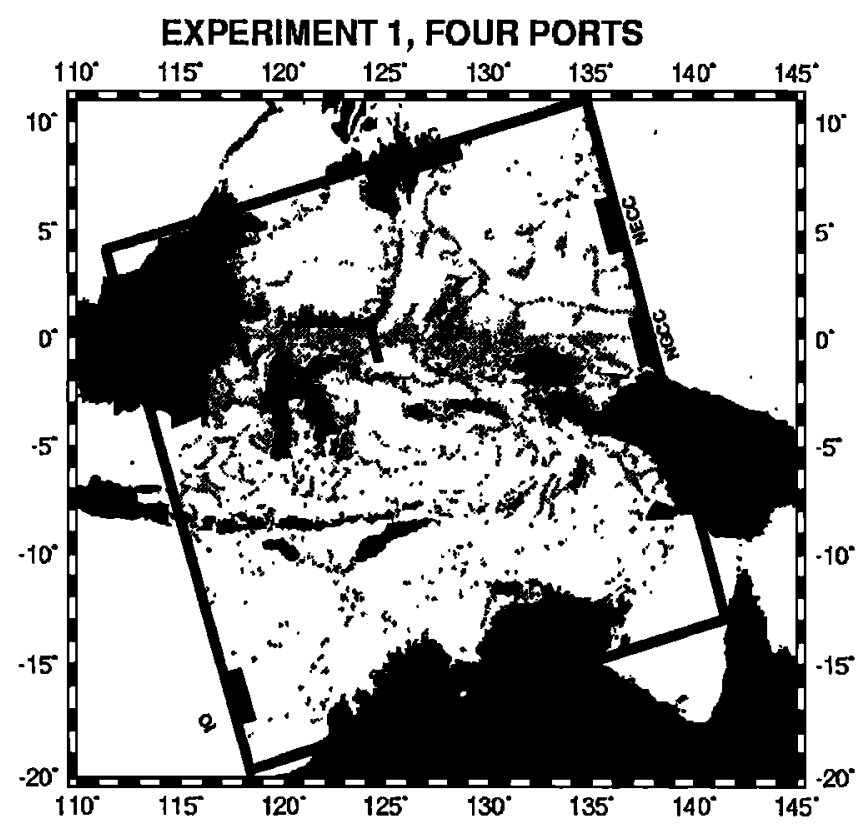

Figure 1. The model domain and the location of the four open ports. In the shaded area the relative error (1) for the Type 1 experiment is greater than 0.1. Lines across the Makassar Strait and the Malucca Sea indicate locations of cross-sections (see caption to Fig. 3).

results are obtained for the relation $f V=g \partial \eta / \partial x$, where $V$ is the y-component of the velocity vector, however due to space limitations we do not present the corresponding figure here.

For Type 2 experiments, the prescribed sea-surface elevations are increased (decreased) by a constant value of $2.5 \mathrm{~mm}$ at the north and east ports and decreased (increased) by a constant value of $4.5 \mathrm{~mm}$ at the western port. Note that in a barotropic model, a $1 \mathrm{~mm}$ increase in $\eta$ corresponds approx-

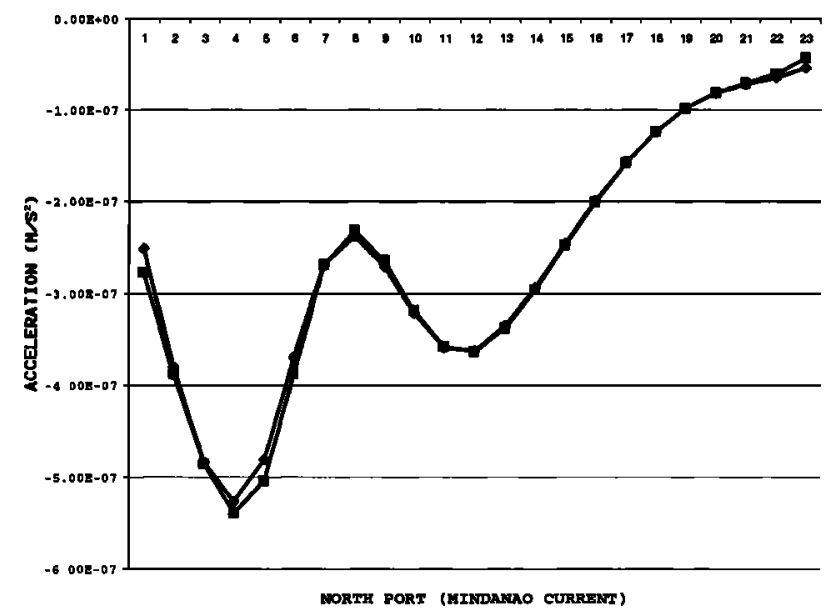

Figure 2. Comparison of the Coriolis acceleration (squares) to the horizontal pressure gradient (diamonds) for the MC port from the Type 1 experiment. The port's grid numbers are labeled along the horizontal axis.
Table 1. The prescribed transports through the open ports.

\begin{tabular}{lr}
\hline Port & Transport, Sv \\
\hline North (MC inflow) & 20.5 \\
West (IO outflow) & 5.0 \\
East (NGCC outflow) & 14.0 \\
East (NECC outflow) & 29.5 \\
\hline
\end{tabular}

imately to a $1 \mathrm{~cm}$ increase in a baroclinic model. Similar to our previous experiments [Burnett et al. 2000], perturbing $\Delta \eta$ more than two times its original value caused a $5 \%-7 \%$ variation in the transports through the north and east ports respectively.

The graphs in Figure 3 show separate terms in the $x$ momentum equation (the Coriolis acceleration, pressure gradient, horizontal momentum diffusion, advection of momentum, and bottom friction) for the cross sections through the Makassar Strait and the Malucca Sea (note locations on Fig. 1). At the equator, horizontal momentum diffusion and, to an order of magnitude less the advection of momentum, balance the horizontal pressure gradient (the horizontal turbulent viscosity is equal to $500 \mathrm{~m}^{2} \mathrm{~s}^{-1}$ ). South of the equator the horizontal momentum diffusion and horizontal pressure gradient balance the Coriolis acceleration. We expect the horizontal momentum diffusion to influence the dynamical balance in the Makassar Strait since most of the passageway is rather narrow. Current meter and CTD station data obtained during the first week of the mooring record as part of the Indonesia-USA Arlindo Program [Gordon et al. 1999] corroborate these model results, as the calculated geostrophic currents exceeded the measured currents by a factor of four and shear by a factor of three.

Our observations are different in the Malucca Sea, where narrow straits do not restrict the flow pattern. Here, the horizontal momentum diffusion and advection of momentum assume a larger role in the dynamical balance while geostrophy is clearly applicable south of the equator. Bottom friction is not a dominant factor at either location. Advection of momentum is on the order of horizontal momentum diffusion in this region due to the western boundary current flowing along the western edge of the Malucca Sea into the Banda Sea.

Table 2 provides an estimate of the overall momentum balance in the $\mathrm{x}$-direction for the Type 1 and 2 experiments. First, we estimated the resultant of pressure forces acting on the side walls of the domain with all islands included. This is the domain integral of $g[\partial(D \eta) / \partial x]$, where $D$ is the total depth, $D=H+\eta$, and $H$ is the depth (given in Table 2 at the top of the table in $10^{8} \mathrm{~m}^{4} \mathrm{~s}^{-2}$ units). Second, we calculated the $x$-integrals of the separate terms in the x-momentum equation along four sections: $D$ (south of IO port), $C$ (between NGCC and IO ports), $B$ (between NECC and NGCC ports), $A$ (north of NECC port). As was expected from the above analysis, the contribution from the horizontal diffusion of momentum, momentum advection, and bottom friction appeared small and the section inte- 
Table 2.

The integrated Coriolis acceleration and pressure gradient terms in the $\mathrm{x}$-momentum equation along four cross sections for the Type 1 experiment (prescribed normal velocities) and Type 2 experiments (perturbed sea surface elevations of $+2.5 \mathrm{~mm}$ (A) and $-2.5 \mathrm{~mm}(\mathrm{~B})$ ). Refer to the text for the location of sections A, B, C, and D and units used.

\begin{tabular}{|c|c|c|c|c|c|c|}
\hline \multirow[b]{3}{*}{ Section } & \multirow{2}{*}{\multicolumn{2}{|c|}{$\begin{array}{c}\text { Experiment } 1 \\
2.64\end{array}$}} & \multicolumn{2}{|c|}{ Experiment $2 \mathrm{~A}$} & \multicolumn{2}{|c|}{ Experiment 2B } \\
\hline & & & & & & \\
\hline & Coriolis & press grad & Coriolis & press grad & Coriolis & press grad \\
\hline A & 3.70 & -3.67 & 3.73 & -3.70 & 3.58 & -3.55 \\
\hline B & -0.44 & 0.45 & -0.57 & 0.59 & -0.30 & 0.31 \\
\hline $\mathrm{C}$ & -1.68 & 1.79 & -2.58 & 2.77 & -0.82 & -0.87 \\
\hline $\mathrm{D}$ & -0.027 & 0.032 & -0.041 & 0.046 & -0.014 & 0.016 \\
\hline
\end{tabular}

grals of $f V D$ and $g D(\partial \eta / \partial x)$ are basically balanced (these integrals in $10^{6} \mathrm{~m}^{3} \mathrm{~s}^{-2}$ units are denoted by 'Coriolis' and 'press grad' in Table 2 respectively). The total transports through the Pacific ports are an order of magnitude higher than the total transport through the Indian Ocean port.

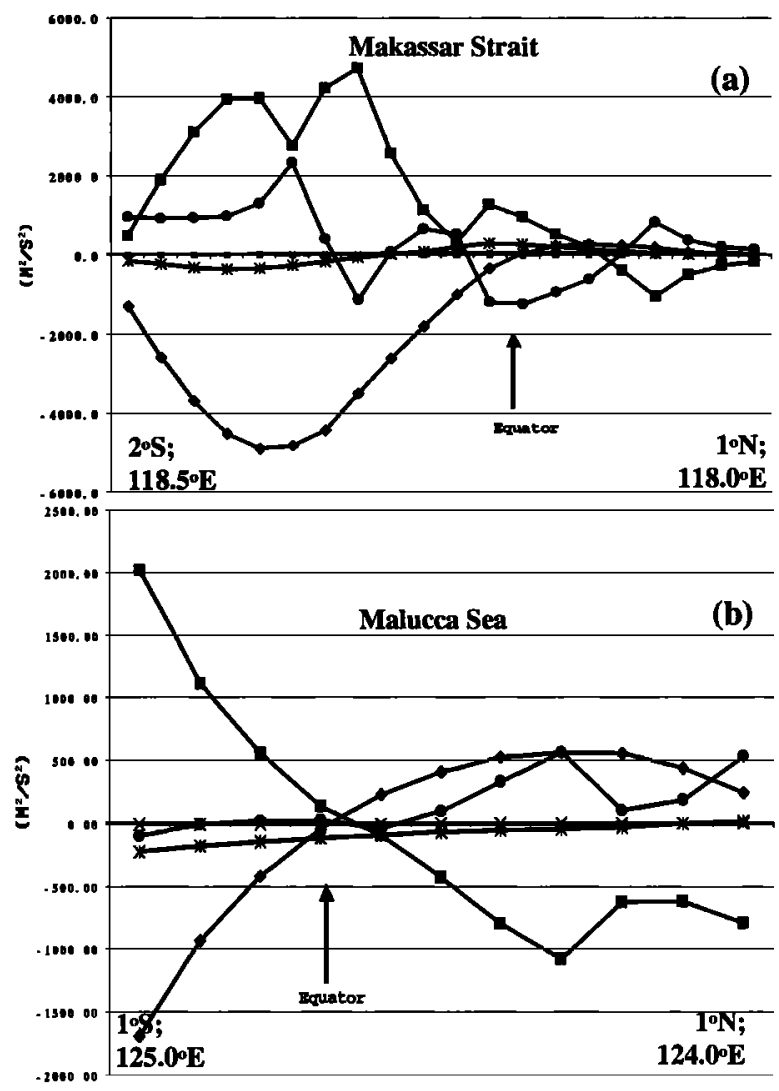

Figure 3. Comparison of the separate terms in the $x$ momentum equation [Coriolis acceleration (diamond), horizontal pressure gradient (square), bottom friction (cross), momentum advection (star), and horizontal momentum diffusion (circle)] from the Type 1 experiment. a) Makassar Strait and (b) Malucca Sea cross sections (see Fig. 1). The beginning and ending of each cross section are labeled.
This causes a loss of accuracy in calculating the section integral of $f V D$ and correspondingly of $g D(\partial \eta / \partial x)$ to the south of the NECC port. To the north of the NECC port these terms are calculated with a sufficient accuracy. As we see from Table 2, the section integral of $g D(\partial \eta / \partial x)$ in this region does not change significantly in experiments 1 and 2A,B. Therefore we argue that the same is true for the domain integral of $g D(\partial \eta / \partial x)$. But Table 2 shows a significant change in the domain integral of $g[\partial(D \eta) / \partial x]$ in these experiments. Thus, we conclude that the changes of the domain integral of $g[\partial(D \eta) / \partial x]$ (the x-component of the resultant of pressure forces acting on the side walls) in experiments 1 and 2A,B are essentially balanced by the changes of the domain integral of $g \eta(\partial D / \partial x)$ (the $\mathrm{x}$-component of the resultant of pressure forces acting on the bottom). Similar results have been obtained for the 3 ports case.

Thus, we have shown that 1) geostrophy is valid throughout most of the Indonesian Seas area and 2) the x-component of the resultant of pressure forces acting on the bottom (the bottom form stress) essentially balance the $x$-component of the resultant of pressure forces acting on the side boundaries. These results lend credence to our hypothesis that the pressure head between the Pacific and Indian Ocean does not significantly influence the Indonesian throughflow. Ageostrophic conditions, however, exist along individual straits and passages within the Indonesian Seas area, primarily along equatorial regions where the horizontal pressure gradient, horizontal momentum diffusion, and momentum advection are the dominant terms in the dynamical balance.

Acknowledgments. The authors gratefully acknowledge discussions with $\mathrm{H}$. Hurlburt. The comments of two anonymous reviewers are greatly appreciated. W. Burnett was supported by U.S. Navy funds. V. Kamenkovich, D. Jaffe, G. Mellor, A. Gordon, were supported by NSF grant OCE 96-33470. The model analysis was supported by the Department of Defense's Major Shared Resource Center supercomputer located at the Naval Oceanographic Office in Stennis Space Center, MS.

\section{References}

Blumberg, A. F., and G. L. Mellor, A description of a threedimensional coastal ocean circulation model, Coastal and Es- 
tuarine Sciences 4, Three-Dimensional Coastal Ocean Models, Amer. Geophys. Union, Washington D.C., 1-16, 1987.

Burnett, W. H., V. M. Kamenkovich, G. L. Mellor, and A. L. Gordon, The influence of the pressure head on the Indonesian Seas circulation, Geophys. Res. Letters, (In Press).

Fieux, M., R. Molcard, and A. G. Ilahude, Geostrophic transport of the Pacific-Indian Oceans throughflow, J. Geophys. Res., $101,12,421-12,432,1996$.

Gordon, A. L., and J. L. McClean, Thermohaline stratification of the Indonesian Seas: model and observations, J. Phys. Oceanogr., 29, 198-216, 1999.

Gordon, A. L., R. D. Susanto, and A. L. Ffield, Throughflow within Makassar Strait, Geophys. Res. Letters, 26(21), 33253328, 1999.

Miyama, T., T. Awaji, K. Akitomo, and N. Imasato, Study of seasonal transport variations in the Indonesian Seas, J. Geophys. Res., 100, 20,517-20,541, 1995.
Murray, S. P., E. Lindstrom, J. Kindle, and E. Weeks, Transport through Vitiaz Strait, WOCE Notes, 7(1), 21-23, 1995.

W. H. Burnett, Naval Meteorology and Oceanography Command,Stennis Space Center, MS 39529; e-mail:BurnettB@cnmoc .navy.mil

A. L. Gordon, Lamont-Doherty Earth Observatory of Columbia University, Palisades, NY 10964.

D. A. Jaffe, University of California, Irvine, CA 92697

V. M. Kamenkovich, Department of Marine Science, The University of Southern Mississippi, Bldg 1103, Stennis Space Center, MS 39529

G. L. Mellor, Program in Atmospheric and Oceanic Sciences, Sayre Hall, Forrestal Campus, Princeton University, Princeton, NJ 08544

(Received February 17, 2000; Accepted May 10, 2000.) 